\title{
Abdominal radiograph in the assessment of fecal impaction in children with functional constipation: comparing three scoring systems
}

\author{
Tatyana Borges da Cunha, ${ }^{1}$ Soraia Tahan, ${ }^{2}$ Maria de Fátima de Faria Soares, ${ }^{1}$ \\ Henrique Manoel Lederman, ${ }^{3}$ Mauro Batista de Morais ${ }^{3}$
}

\begin{abstract}
Objectives: To compare three radiological scores in the study of fecal impaction in children with constipation. To investigate whether these radiological scores are useful in the assessment of fecal disimpaction therapy and if they present a relation with total colonic transit time.

Methods: The Barr, Blethyn and Leech scores were measured by three observers, independently, in 123 abdominal radiographs. Interobserver agreement in the diagnosis of fecal impaction was calculated for the three scores. In 30 radiographs, the analysis of the scores was performed before and after fecal disimpaction. Total colonic transit time was calculated in 59 radiographs with the use of radiopaque markers.

Results: The agreement between pairs of observers was assessed by the kappa coefficient and was good for the Barr $(0.56,0.59$ and 0.69$)$ and Leech scores $(0.53,0.58$ and 0.61). The Blethyn score presented lower kappa coefficients $(0.26,0.32$ and 0.36$)$. In the comparison of methods, Leech and Barr showed a good correlation. After fecal disimpaction, there was a statistically significant reduction $(p<0.001)$ of scores, most significantly with the Barr score. There was no relation between radiographic scores and colonic transit time.

Conclusions: There is no relation between fecal impaction assessed by radiography of the abdomen and total colonic transit time. Plain radiographs may be a useful tool for the diagnosis of fecal impaction. The Barr score can be considered a good method of analysis, especially to assess the response to treatment of fecal impaction.

J Pediatr (Rio J). 2012;88(4):317-22: Intestinal constipation, fecal impaction, abdominal radiograph, methods, child.
\end{abstract}

\section{Introduction}

Chronic constipation can cause fecal incontinence by retention, which causes reduction in quality of life, school absences, social discrimination and low self-esteem. ${ }^{1-5}$ The characterization of fecal impaction followed by the effective emptying of the colon is considered one of the indispensable foundations for the successful treatment of intestinal constipation. ${ }^{1,2}$ Not always the physical examination shows clear signs of fecal impaction. Abdominal palpation may be difficult and the realization of digital rectal examination is not always possible. ${ }^{3}$ In this context, plain abdominal radiograph has been used in the assessment of fecal impaction. 6,7 The North-American Society for Pediatric Gastroenterology, Hepatology and Nutrition ${ }^{1}$ recommends plain abdominal radiograph for the characterization of fecal impaction in the following conditions: obesity; refusal to perform digital rectal examination; psychological problems such as, for

1. MSc. Escola Paulista de Medicina, Universidade Federal de São Paulo (UNIFESP), São Paulo, SP, Brazil.

2. PhD. Escola Paulista de Medicina, UNIFESP, São Paulo, SP, Brazil.

3. Tenured professor. Escola Paulista de Medicina, UNIFESP, São Paulo, SP, Brazil.

No conflicts of interest declared concerning the publication of this article.

Suggested citation: da Cunha TB, Tahan S, Soares MF, Lederman HM, de Morais MB. Abdominal radiograph in the assessment of fecal impaction in children with functional constipation: comparing three scoring systems. J Pediatr (Rio J). 2012;88(4):317-22.

Manuscript submitted Jan 13 2012, accepted for publication Mar 282012.

http://dx.doi.org/10.2223/JPED.2199 
example, victims of sexual abuse, for whom the digital rectal examination can be traumatic; a very suggestive history of constipation with fecal impaction, but with the absence of feces in the rectal ampulla. ${ }^{1}$ The abdominal radiograph may also be useful in cases of hidden constipation. ${ }^{2}$

However, in clinical practice, there is no consensus on criteria for analyzing abdominal radiographs of patients with chronic constipation. In 1979, Barr et al. ${ }^{8}$ designed a score that assesses the fecal retention on abdominal radiographs. Later, in $1995^{9}$ and 1999,10 other scores (Blethyn and Leech) were developed with the same goal. Few studies have compared these radiological scores and they used heterogeneous frameworks and analytical methods. ${ }^{11-18}$ This study differs from the literature by analyzing all three radiographic scores simultaneously, using only indicators of reproducibility, and not using indexes dependent on a gold standard, which does not exist for the definition of fecal impaction, and analyzing for the first time in literature a number of radiological examinations performed before and after disimpaction.

Thus, this study was performed to compare three radiological scores (Baar, ${ }^{8}$ Blethyn ${ }^{9}$ and Leech ${ }^{10}$ ) in the study of fecal impaction in children with intestinal constipation. It was also verified if these radiological scores are useful in assessing fecal disimpaction therapy and if they had a relation to total colonic transit time (TCTT).

\section{Methods}

123 abdominal radiographs of children with chronic functional constipation were assessed, retrospectively. The radiographs were used in three previous studies of the Clinic of Digestive Motility Disorders of the Pediatric Gastroenterology Chair (Ambulatório de Distúrbio da Motilidade Digestiva da Disciplina de Gastroenterologia Pediátrica) of Escola Paulista de Medicina, Universidade Federal de São Paulo, Brazil.

The three studies were the following:

1) A clinical trial conducted to assess the efficacy of a soy polysaccharide fiber in the treatment of chronic functional constipation in children, which assessed 30 children with a 90 months average age (percentile 25 and $95=54.3$ and 121.7 months), 20 of whom were male. ${ }^{19}$ On admission, $48.7 \%$ (19/39) had fecal incontinence by retention, $76.7 \%$ (23/30), palpable abdominal mass and $63.3 \%(19 / 30)$, feces in the rectal ampulla. To determine the TCTT, radiographs were performed with markers according to the technique described by Metcalf et al. ${ }^{20}$ which indicates radiological examination in the fourth and seventh days after the ingestion of the marker and, if necessary, on the 10th day. Of the 30 children, 25 underwent radiographs in the fourth and seventh day after beginning treatment, and five also on the 10 th day, in a total of 65 radiographs.
2) A clinical trial conducted to assess the efficacy of a fiber mixture in the treatment of functional chronic constipation in children. ${ }^{21} 24$ children were assessed. They underwent radiography with markers for determining the TCTT according to the technique described by Gutierrez et al., ${ }^{22}$ which indicates radiographs on the seventh day after ingesting markers for 6 days. 24 abdominal radiographs with radiopaque markers were obtained.

3) A randomized study to assess the efficacy of a high dose of mineral oil in comparison with the use of enemas for the treatment of fecal impaction. 20 patients were included, with an average age of 6.6 years (percentile 25 and $75=3.9$ and 8.6 years), of which 18 were male. 23 The clinical manifestations were fecal incontinence by retention (95\%), palpable abdominal mass ( $85 \%$ ) and digital rectal examination with feces in the rectal ampulla in all patients. Of these, 15 underwent plain abdominal radiograph before and after being treated for fecal impaction, and four, only when beginning treatment (note: a child made no radiograph), in a total of 34 radiographs.

In all three studies children with a clinical diagnosis of chronic functional constipation were assessed, and only in the study that assessesd the efficacy of mineral oil23 it was required, on admission, the presence of fecal impaction on abdominal palpation and/or digital rectal examination. Children with suspected organic causes of constipation were excluded, such as patients with congenital megacolon, anorectal malformations and constipation secondary to cow's milk allergy.

The dates and names that appeared on the radiographs were covered by labels, to prevent the evaluator to be aware of the protocols or stage to which the radiographs belonged. The total set of radiological images was listed in a way that did not put the radiographs of the same patient in sequence, considering these were made at different times of the treatment or the TCTT study. Thus, the evaluator was unaware of to which patient belonged each of the radiographs, if it had been made before or after treatment and, in the case of radiographs with markers, if it was from the fourth or seventh day after the ingestion of the radiopaque markers.

The radiographs were assessed independently by three observers without knowledge of any clinical information: two pediatric gastroenterologists and a radiologist with experience in pediatrics. The observers analyzed the 123 radiographs following a script prepared in advance by the authors, containing a summary description of the three radiographic scores (Barr, ${ }^{8}$ Blethyn $^{9}$ and Leech ${ }^{10}$ ).

In summary, the assessment of the Barr et al. ${ }^{8}$ radiographic score was based on the amount and appearance of the feces. The amount of feces was assessed in four colonic segments: ascending colon, transverse colon, descending 
colon and rectum. The amount of feces in each segment was classified as low, moderate and large, according to a specific score. The presence of dilated segments in the large intestine was also considered. The appearance of the feces was classified as rocky or granular, considering also their topographical distribution. Fecal impaction was characterized as the score was equal to or higher than 10 , as recommended. 8

In evaluating the radiographic score of Blethyn et al. ${ }^{9}$ the presence of fecal impaction was based on the amount and location of the feces, as well as the presence of colonic dilatation. In grade 0 (normal), feces appear only in the cecum and rectum. In grade 1 , there are feces in the rectum, cecum and colon in some areas. Grade 2 is characterized by the presence of feces in the rectum, cecum and colon throughout. Grade 3 is characterized when the feces are found in the rectum, cecum and throughout the colon, with dilatation and impaction in the rectum. Grades 2 and 3 were considered positive for the presence of fecal impaction. ${ }^{9}$

The Leech et al. ${ }^{10}$ radiographic score uses a classification ranging from 0 to 5 , with 0 equal to no feces; 1 , scant feces; 2, few impacted feces; 3, moderate amount of impacted feces; 4, large amount of impacted feces, and 5, a large amount of impacted feces with colonic dilatation. This score is applied in three colonic segments, i.e., right, left and rectosigmoid colon, defined by three anatomical reference points: the fifth lumbar vertebra, right anterior-posterior iliac spine and left iliac crest. The score can range from 0 to 15 , with scores $\geq 9$ suggestive of severe intestinal constipation. 10

TCTT was calculated in 59 radiographs with the use of radiopaque markers (Sitzmarks ${ }^{\circledR}$, Konsyl Pharmaceuticals, Easton, MD, USA) according to the techniques described by Metcalf et al. ${ }^{20}$ or by Gutierrez et al. ${ }^{22} \mathrm{~A}$ threshold of normality of 62 hours was adopted. 24

In statistical analyses the Friedman test for repeated measures (comparing the scores of the three observers) and the paired Student's $t$ test to compare the values of the scores before and after disimpaction were used. The agreement between pairs of observers was assessed by the kappa coefficient, in which values below 0.20 indicate a very slight agreement; 0.21 to 0.40 , mild; 0.41 to 0.60 , moderate; 0.61 to 0.80 , substantial; and 0.81 to 1.00 , an almost perfect agreement. ${ }^{25}$ The Pearson coefficient was used in the correlation between pairs of observers, in which values equal to 0 indicate no correlation; between 0 and 0.30 , weak; 0.31 and 0.60 , regular; 0.61 and 0.90 , strong; 0.91 and 1.00 , very strong; and equal to 1.00 , full or perfect. 26 The McNemar test was used to assess the correlation between the presence of increased TCTT and radiographic score suggestive of fecal impaction. To calculate the statistical tests, the software SigmaStat version 3.5 was used (Systat Software, San Jose, California, USA). Regarding the size of the sample, according to the
SigmaStat software, 42 radiographs would be enough to identify statistical significance for a coefficient of correlation of 0.50 , considering an alpha error of $1 \%$ and an $80 \%$ power. Thus, it was considered that 123 radiographs would be sufficient for this study.

This project was approved by the Research Ethics Committee of Universidade Federal de São Paulo (project number: 1772/09).

\section{Results}

To assess the degree of interobserver agreement, the kappa coefficient was used (Table 1). The Blethyn method showed poor interobserver agreement. For the Leech and Barr methods, there was moderate to substantial agreement. Although the Barr and Leech scores have shown very similar coefficients, higher values were observed with Barr. The Pearson coefficient between pairs of examiners showed a statistically significant correlation for all three scores (Table 1). The correlation was weak for the Blethyn method and strong for the Barr and Leech methods. The methods of radiological scores were compared in pairs through the Pearson correlation coefficient. For the three observers, the method Blethyn showed no correlation to the Leech (Pearson coefficients of $0.09,-0.13$ and -0.04 for observers 1,2 and 3 , respectively) and Barr scores (-0.04, -0.03 and 0.14). The Leech and Barr methods had excellent correlation with statistical significance for three observers (coefficients of $0.77,0.66$ and 0.68$)$.

Table 2 shows the variation in radiological scores before and after fecal disimpaction. The Blethyn method showed no significant changes in scores before and after. According to an observer, the scores increased when their reduction would be expected. Regarding the Barr and Leech methods, there was a statistically significant reduction in scores after treatment, especially for the Barr method, which presented a higher variation in the percent delta in the analyses by the three examiners.

TCTT was calculated in 59 radiographs, and in 15 $(25.4 \%$ ) the value was high (> 62 hours). The correlation between TCTT and the radiological scores was measured through the McNemar test and the kappa coefficient (Table 3). The McNemar test showed a statistically significant disagreement in all analyses, except in the assessment of Barr and Leech scores by observer 3. The kappa coefficient confirmed the poor correlation between TCTT and radiological scores for all observers, ranging from very mild to mild (kappa < 0.40).

\section{Discussion}

In the assessment of fecal impaction using plain abdominal radiographs with three radiographic scores performed in his study, it was observed that the $\mathrm{Barr}^{8}$ and 
Table 1 - Pearson and kappa coefficients of correlation in the analysis of the interobserver agreement for the different methods

\begin{tabular}{|c|c|c|c|c|}
\hline Score & Coefficient & Observer $1 \times 2$ & Observer $1 \times 3$ & Observer $2 \times 3$ \\
\hline \multirow[t]{2}{*}{ Blethyn } & Kappa & 0.36 & 0.32 & 0.26 \\
\hline & Pearson & $0.34 *$ & $0.39 *$ & $0.41 *$ \\
\hline \multirow[t]{2}{*}{ Leech } & Kappa & 0.61 & 0.58 & 0.53 \\
\hline & Pearson & $0.65^{*}$ & $0.69 *$ & $0.74 *$ \\
\hline \multirow[t]{2}{*}{ Barr } & Kappa & 0.69 & 0.59 & 0.56 \\
\hline & Pearson & $0.61^{*}$ & $0.67 *$ & $0.69 *$ \\
\hline
\end{tabular}

" $p<0.001$.

Table 2 - Comparison of scores before and after $(n=30)$ fecal impaction treatment

\begin{tabular}{|c|c|c|c|c|c|c|}
\hline Score & Observer & Before & After & Difference & Percent delta $(\%)$ & p* \\
\hline \multirow[t]{3}{*}{ Blethyn } & 1 & $1.60 \pm 0.83$ & $1.87 \pm 0.52$ & $-0.23 \pm 0.96$ & -15.6 & 0.3 \\
\hline & 2 & $2.85 \pm 0.56$ & $1.69 \pm 1.38$ & $1.15 \pm 1.28$ & 51.1 & 0.07 \\
\hline & 3 & $2.53 \pm 0.64$ & $2.47 \pm 0.52$ & $0.07 \pm 0.59$ & 2.4 & 0.67 \\
\hline \multirow[t]{3}{*}{ Leech } & 1 & $11.93 \pm 2.37$ & $6.40 \pm 2.41$ & $5.53 \pm 1.92$ & 60.3 & $<0.001$ \\
\hline & 2 & $11.21 \pm 3.40$ & $5.57 \pm 4.15$ & $5.64 \pm 3.99$ & 67.2 & $<0.001$ \\
\hline & 3 & $9.67 \pm 3.3$ & $4.3 \pm 2.8$ & $5.3 \pm 3.02$ & 76.9 & $<0.001$ \\
\hline \multirow[t]{3}{*}{ Barr } & 1 & $17.47 \pm 4.67$ & $6.47 \pm 4.48$ & $11.00 \pm 4.09$ & 91.9 & $<0.001$ \\
\hline & 2 & $13.27 \pm 5.08$ & $6.53 \pm 5.17$ & $6.73 \pm 4.48$ & 68 & $<0.001$ \\
\hline & 3 & $13.07 \pm 6.01$ & $4.07 \pm 3.41$ & $9.00 \pm 5.50$ & 105 & $<0.001$ \\
\hline
\end{tabular}

*Paired Student's $t$ test.

Leech $^{10}$ scores have a good interobserver agreement and a good correlation between pairs of observers. The Barr ${ }^{8}$ score had the highest coefficients. On the other hand, the Blethyn ${ }^{9}$ score presented the worst coefficients. The Barr ${ }^{8}$ score requires a more detailed analysis, because it assesses not only the amount and disposition of feces in the colon as well as the appearance of these compared to what is usually found. The Barr score seems to be a difficult and extensive method; however, there was no difficulty in its application.

In literature, the findings are contradictory regarding the utility of radiography in the diagnosis of fecal impaction. In part, the lack of agreement is due to the very differences of each radiological score. In 2006, a study compared the three scores (Barr, Blethyn and Leech) and found better results for the Leech score. ${ }^{11}$ Another work, more recent, published in 2010,12 showed low agreement between the three scores. For the Blethyn score, a weak reproducibility can be observed in literature, as it is in the results of the present study. ${ }^{11,12,15}$ The Blethyn score has a more simplified and subjective system of analysis, which may explain its limited reproducibility.

This study is the only one in literature that examines the usefulness of abdominal radiographs in the assessment of the response to the treatment of impaction. ${ }^{23}$ Our patients underwent radiography before and after effective fecal disimpaction. After effective disimpaction, it is expected that the scores decrease, tending to normality, since the colon should not be filled with a large amount of feces. Our results showed a significant decrease in scores after disimpaction, 
Table 3 - Agreement between total colonic transit time and the Blethyn, Leech and Barr scores

\begin{tabular}{|c|c|c|c|c|c|c|}
\hline \multirow[t]{2}{*}{ Score } & \multirow[t]{2}{*}{ Observer } & \multirow{2}{*}{$\begin{array}{c}\text { Fecal } \\
\text { impaction }\end{array}$} & \multicolumn{2}{|c|}{ Total colonic transit time } & \multirow[b]{2}{*}{ p* } & \multirow{2}{*}{$\begin{array}{c}\text { kappa } \\
\text { coefficient }\end{array}$} \\
\hline & & & $\geq 62$ hours & $<62$ hours & & \\
\hline \multirow[t]{6}{*}{ Blethyn } & 1 & Yes & 11 & 26 & $<0.001$ & 0.12 \\
\hline & & No & 4 & 18 & & \\
\hline & 2 & Yes & 13 & 29 & $<0.001$ & 0.13 \\
\hline & & No & 2 & 13 & & \\
\hline & 3 & Yes & 15 & 36 & $<0.001$ & 0.10 \\
\hline & & No & 0 & 8 & & \\
\hline \multirow[t]{6}{*}{ Leech } & 1 & Yes & 13 & 21 & $<0.001$ & 0.28 \\
\hline & & No & 2 & 23 & & \\
\hline & 2 & Yes & 11 & 17 & 0.008 & 0.31 \\
\hline & & No & 4 & 26 & & \\
\hline & 3 & Yes & 11 & 10 & 0.181 & 0.44 \\
\hline & & No & 4 & 34 & & \\
\hline \multirow[t]{6}{*}{ Barr } & 1 & Yes & 13 & 19 & $<0.001$ & 0.29 \\
\hline & & No & 2 & 25 & & \\
\hline & 2 & Yes & 11 & 12 & 0.008 & 0.31 \\
\hline & & No & 4 & 32 & & \\
\hline & 3 & Yes & 9 & 14 & 0.181 & 0.44 \\
\hline & & No & 6 & 30 & & \\
\hline
\end{tabular}

* McNemar test.

with statistical significance for the Barr ${ }^{8}$ and Leech ${ }^{10}$ scores. However, this did not happen with the Blethyn ${ }^{9}$ score. The finding of significantly lower scores after the treatment of fecal impaction shows that abdominal radiography is a good instrument to assess the effectiveness of the treatment used. Moreover, assessments before and after effective fecal disimpaction strengthened the results of this study, since the individual assessments of the radiographs were made with the observers being unaware of any clinical information.

The sole limitation of this study, as well as of all the literature on the subject, is the lack of a gold standard to define fecal impaction, which impedes the calculation of sensitivity, specificity and ROC curve construction to allow more detailed analysis of the diagnostic performance of the different scores, considering different cutoff points. The poor agreement between the three scores and the colonic transit time in this study has also been observed in several other studies. ${ }^{13-15}$ In our study, $25.4 \%$ of the radiographs showed an increase of TCTT, while other studies using radiopaque markers show an increase in colonic transit time in 42 to $61 \%$ of children with chronic constipation. $7,24,27,28$ It is worth remembering that the clinical significance of fecal impaction and increased colonic transit time are not exactly equal, which is why the existence of a correlation between fecal impaction and colonic dysmotility would not be mandatory. Therefore, the use of colonic transit time with radiopaque markers as a framework for fecal impaction is questionable.

Moreover, the terms constipation and fecal impaction are often used wrongly, and often considered synonymous. Thus, in clinical practice, it is important to differentiate the presence of fecal impaction, requiring the availability of a diagnostic method to identify these patients in the group of children with constipation, since the effective disimpaction of the colon is a key factor for good response to treatment. 1,2

Given the above, it is concluded that the analysis of the plain abdominal radiograph is a useful tool to characterize fecal impaction and to assess the response to its treatment. The analyses of the radiographs through the scores proved interesting, showing limitations in the use of the Blethyn method and better coefficients with the Barr and Leech scores. The Barr score, because of the complexity of analysis, including the assessment of both the amount and appearance of the feces in the colonic segments, seemed at first to be difficult to implement. However, when interpreting the radiographs, the Barr score provided more adequate results. Although the coefficients of agreement and correlation between Barr 
and Leech scores have been very similar in the analysis of scores before and after fecal disimpaction, the Barr score showed the higher variation. Thus, among the three radiographic scores used, the Barr score should be a method of choice to diagnose fecal impaction with the use of plain abdominal radiographs. No relation was observed between the intensity of fecal impaction on plain radiographs and the increase in colonic transit time. The analysis of plain abdominal radiograph was useful in assessing the effectiveness of fecal disimpaction.

\section{References}

1. Constipation Guideline Committee of the North American Society for Pediatric Gastroenterology, Hepatology and Nutrition. Evaluation and treatment of constipation in infants and children: recommendations of the North American Society for Pediatric Gastroenterology, Hepatology and Nutrition. J Pediatr Gastroenterol Nutr. 2006;43:e1-13.

2. Morais MB, Tahan S. Constipação intestinal. Pediatr Mod. 2009;45:79-98.

3. Candy D, Paul S. Go with the flow: in childhood constipation. J Fam Health Care. 2011;21:35-41.

4. Lisboa VC, Felizola MC, Martins LA, Tahan S, Neto UF, de Morais MB. Aggressiveness and hostility in the family environment and chronic constipation in children. Dig Dis Sci. 2008;53:2458-63.

5. Tabbers MM, Boluyt N, Berger MY, Benninga MA. Clinical practice: diagnosis and treatment of functional constipation. Eur J Pediatr. 2011;170:955-63.

6. Reuchlin-Vroklage LM, Bierma-Zeinstra S, Benninga MA, Berger MY. Diagnostic value of abdominal radiography in constipated children: a systematic review. Arch Pediatr Adolesc Med. 2005; $159: 671-8$

7. Bongers ME, VoskuijI WP, van Rijn RR, Benninga MA. The value of the abdominal radiograph in children with functional gastrointestinal disorders. Eur J Radiol. 2006;59:8-13.

8. Barr RG, Levine MD, Wilkinson RH, Mulvihill D. Chronic and occult stool retention: a clinical tool for its evaluation in school-aged children. Clin Pediatr (Phila). 1979;18:674-9.

9. Blethyn AJ, Verrier Jones K, Newcombe R, Roberts GM, Jenkins HR. Radiological assessment of constipation. Arch Dis Child. 1995; 73:532-3.

10. Leech SC, McHugh K, Sullivan PB. Evaluation of a method of assessing faecal loading on plain abdominal radiographs in children. Pediatr Radiol. 1999;29:255-8.

11. van den Bosch M, Graafmans D, Nievelstein R, Beek E. Systematic assessment of constipation on plain abdominal radiographs in children. Pediatr Radiol. 2006;36:224-6.

12. Moylan S, Armstrong J, Diaz-Saldano D, Saker M, Yerkes EB, Lindgren BW. Are abdominal x-rays a reliable way to assess for constipation? J Urol. 2010;184:1692-8.

13. Benninga MA, Büller HA, Staalman CR, Gubler FM, Bossuyt PM, van der Plas RN, et al. Defaecation disorders in children, colonic transit time versus the Barr-score. Eur J Pediatr. 1995;154:277-84.
14. de Lorijn F, van Rijn RR, Heijmans J, Reitsma JB, Voskuijl WP, Henneman OD, et al. The Leech method for diagnosing constipation: intra- and interobserver variability and accuracy. Pediatr Radiol. $2006 ; 36: 43-9$.

15. Jackson CR, Lee RE, Wylie AB, Adams C, Jaffray B. Diagnostic accuracy of the Barr and Blethyn radiological scoring systems for childhood constipation assessed using colonic transit time as the gold standard. Pediatr Radiol. 2009;39:664-7.

16. Pensabene L, Buonomo C, Fishman L, Chitkara D, Nurko S. Lack of utility of abdominal $\mathrm{x}$-rays in the evaluation of children with constipation: comparison of different scoring methods. J Pediatr Gastroenterol Nutr. 2010;51:155-9.

17. Rockney RM, McQuade WH, Days AL. The plain abdominal roentgenogram in the management of encopresis. Arch Pediatr Adolesc Med. 1995;149:623-7.

18. Koh H, Lee MJ, Kim MJ, Shin JI, Chung KS. Simple diagnostic approach to childhood fecal retention using the Leech score and Bristol stool form scale in medical practice. J Gastroenterol Hepatol. 2010;25:334-8.

19. Motta ME. Ensaio clínico randomizado duplo-cego da eficácia da fibra alimentar do polissacarídeo de soja no tratamento da constipação crônica [tese]. São Paulo: Universidade Federal de São Paulo; 2003

20. Metcalf AM, Phillips SF, Zinsmeister AR, MacCarty RL, Beart RW, Wolff BG. Simplified assessment of segmental colonic transit. Gastroenterology. 1987;92:40-7.

21. WeberTK. Ensaio clínico randomizado, duplo-cego, controlado por placebo sobre o efeito de uma mistura de fibras no tratamento de manutenção e tempo de trânsito colônico total e segmentar de crianças com constipação crônica [tese]. São Paulo: Universidade Federal de São Paulo; 2011.

22. Gutiérrez C, Marco A, Nogales A, Tebar R. Total and segmental colonic transit time and anorectal manometry in children with chronic idiopathic constipation. J Pediatr Gastroenterol Nutr. 2002;35:31-8.

23. Cunha TB, Fukushima E, Tahan S, Morais MB. Eficácia de altas doses de óleo mineral por via oral no tratamento de fecaloma. Rev Chil Nutr. 2009;36:1002.

24. Arhan P, Devroede G, Jehannin B, Lanza M, Faverdin C, Dornic $C$, et al. Segmental colonic transit time. Dis Colon Rectum. $1981 ; 24: 625-9$

25. Landis JR, Koch GG. The measurement of observer agreement for categorical data. Biometrics. 1977;33:159-74.

26. Callegari-Jacques SM. Bioestatística: princípios e aplicações. Porto Alegre: Artmed; 2003.

27. Soares AC, Tahan S, Morais MB. Effects of conventional treatment of chronic functional constipation on total and segmental colonic and orocecal transit times. J Pediatr (Rio J). 2009;85:322-8.

28. de Lorijn F, van Wijk MP, Reitsma JB, van Ginkel R, Taminiau JA, Benninga MA. Prognosis of constipation: clinical factors and colonic transit time. Arch Dis Child. 2004;89:723-7.

Correspondence:

Mauro Batista de Morais

Rua Pedro de Toledo, 443

CEP 04039-031 - São Paulo, SP - Brazil

Tel. : +55 (11) 5579.5834

E-mail: mbmorais@osite.com.br 